\title{
A clinical study on maternal heart diseases complicating pregnancy at tertiary care hospital
}

\author{
Shyamsundar B, Vinayraju D, Seeta Garag \\ Corresponding author: Dr. Vinayraju D, Department of Obstetrics and Gynecology, KIMS, Hubli, \\ Karanataka, India; Email : vinayraju319@gmail.com
}

Distributed under Attribution-Non Commercial - Share Alike 4.0 International (CC BY-NC-SA 4.0)

\begin{abstract}
Background: Cardiac diseases complicate 1- 4\% of pregnancies in women without pre-existing cardiac abnormalities. Cardiac disease in the pregnant woman can present a challenge to the obstetrician, cardiologist and neonatologist. Objectives: Aim is to study the burden of the disease, maternal and neonatal outcome in the cardiac disease complicating pregnancy. Methods: This study is a prospective observational study conducted among the antenatal women admitted in the department of OBG at KIMS, Hubli with a previously diagnosed cardiac disease or diagnosed after admission during index pregnancy from December 2016 to may 2018. The mothers and the babies were followed up till discharge. Maternal outcome was noted as discharged or died. The perinatal outcome was noted in terms of death, presence of congenital heart disease or other anomalies. Results: A total of 66 patients with cardiac disease among 16519 deliveries, were included in the study constituting the prevalence rate of $0.39 \%$. Maximum number of the patients are in the age group between 20-24 year (65.8\%). RHD (Rheumatic heart disease) being the commonest constituting $53.9 \%(\mathrm{~N}=41)$. Among 41 RHD isolated MS (Mitral stenosis) found among 19 cases the dominant lesion. CHD (Congenital heart disease) being the second commonest found in 17 cases with VSD (Ventricular septal defect) being commonest. About 9 newborns had CHD detected in echocardiogram. $61.8 \%$ of the patients delivered vaginally. There were 5 maternal deaths due to cardiac disease. Conclusion: As RHD was common in rural population, and the need for penicillin prophylaxsis among them in adolescent girls. The facilities for cardiac surgery should be made available at affordable prices will definitely go a long way in reducing the mortality and morbidity related to cardiac disease. It is also necessary to follow up these patients in their future pregnancies.
\end{abstract}

Keywords: Cardiac diseases, RHD, CHD, MS,VSD, maternal outcome.

Pregnancy has a significant effect on cardiovascular system. Most of the cardiac conditions in the pregnancy are associated with both maternal and fetal morbidity and mortality. However with improved medical care most of the women are delivering safely ${ }^{1}$. Although cardiac diseases complicate around $0.2-4 \%$ of pregnancies only, it is major indirect cause for maternal mortality. Pregnant women with cardiac disease fall into two categories -

1. Those with diagnosed heart disease and under treatment even before becoming pregnant

2. Those with previously undiagnosed heart disease ${ }^{2}$

Rheumatic heart disease still remains the commonest etiological factor for heart disease complicating pregnancy in under developed countries. It is because of frequent streptococcal infections during childhood days especially in rural areas with poor sanitary conditions. In many pregnant women, heart diseases are diagnosed only when complications develop, the presence of other obstetrical

Received: $3^{\text {rd }}$ June 2020, Peer review completed: $8^{\text {th }}$ July 2020, Accepted: $12^{\text {th }}$ July 2020.

Shyamsundar B, Vinayraju D, Garag S. A clinical study on maternal heart diseases complicating pregnancy at tertiary care hospital. The New Indian Journal of OBGYN. 2021; 7(2): 219-23. 
The New Indian Journal of OBGYN. 2021 (January-June);7(2)

comorbidities further increases the morbidity and mortality, anemia being one of the most common among that. Heart disease is one of the 3 major indirect causes of maternal mortality in india ${ }^{3}$.

Aims and objectives -

1. To know the burden of heart disease complicating pregnancy in our hospital.

2. To record the complications, maternal and neonatal outcome.

3. To determine the incidence of cardiac disease in newborns of cardiac patients.

\section{Materials and methods}

The present study was conducted among the antenatal women admitted in the department of OBG at KIMS, Hubli with a previously diagnosed cardiac disease or diagnosed after admission during index pregnancy from December 2016 to may 2018.

Inclusion criteria:

1. All women admitted to the antenatal ward and labour room with previously diagnosed cardiac disease and women diagnosed during the index pregnancy

2. Women developing cardiac complications during puerperium.

Exclusion criteria:

1. Patients with cardiac disease receiving outpatient care.

2. Patients diagnosed with Peripartum cardiomyopathy

Present study is a prospective observational study. Considering inclusion and exclusion criteria, selected patients were counseled regarding the study. After obtaining valid consent, a predesigned proforma was used. Detailed clinical history regarding the number of pregnancies, presence of cardiac illness, symptoms, treatment received was noted. Necessary obstetrical examination was done. 2D ECHO (Echocardiogram) of the newborns was done to detect undiagnosed cardiac lesions. The mothers and the babies were followed up till discharge. Maternal outcome was noted as discharged or died. The perinatal outcome was noted in terms of normal healthy baby, death or presence of congenital heart disease.

Data were entered in Excel spreadsheet as master chart and analysed using SPSS version 20. Continuous variables were summarized as mean (Standard deviation). Categorical variables were summarized as proportions (percentages).

\section{Results}

Out of 16519 deliveries, 66 patients had cardiac disease, accounting for $0.39 \%$ of prevalence rate. Maximum numbers of the patients are found among the age group of 20-24 years, around $60 \%$ (table 1 ).

Table 1: Age distribution

\begin{tabular}{lll}
\hline Age in years & Number & $\mathbf{\%}$ \\
\hline $20-24$ & 40 & 60.6 \\
$25-29$ & 18 & 27.27 \\
30 and above & 8 & 12.13 \\
Total & 66 & 100 \\
Mean age (Mean \pm St Deviation) & $24.1 \pm 3.2$ &
\end{tabular}

Considering the parity status multigravidas are slightly more in number than primigravida in our study $56.6 \%$ and $43.4 \%$ respectively. Most of the patients were delivered by term gestation. More than $76 \%$ of the patients delivered after the completion of 37 weeks of gestation age. RHD being the dominant cardiac condition (62\%), found in our study followed by CHD (table 2). Chronic pulmonary hypertension found in 3 cases with no cause detected. Ischemic heart disease found in 2 patients. Each case of dilated cardiomyopathy detected antenatally, atrial fibrillation and arrhythmia. MS being the dominant lesion among RHD (figure 1) and isolated MS found in around 19 patients (46\%). Out of 41 RHD patients 21 are found to be positive with ASO antibodies. VSD was the commonest lesion among CHD (figure 2) constituting for more than $40 \%$.

Table 2: Overall cardiac disease

\begin{tabular}{lll}
\hline Cardiac disease & Number & Percentage \\
\hline RHD & 41 & 62.12 \\
CHD & 17 & 25.75 \\
Miscellaneous & 8 & 12.13 \\
Total & 66 & 100 \\
\hline RHD - Rheumatic heart disease, CHD - Congenital heart disease
\end{tabular}

About 20 patients underwent repair surgeries for their preexisting cardiac conditions (table 3). Hence around 70\%

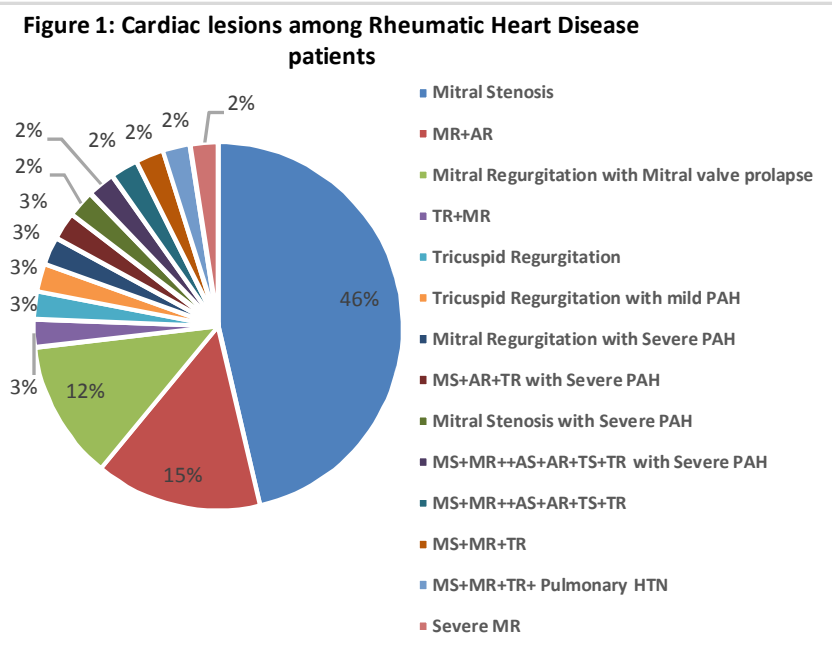


The New Indian Journal of OBGYN. 2021 (January-June);7(2)

of the patients had unrepaired cardiac lesion. As we saw anemia the most significant preexisting comorbid condition worsening the cardiac status found in $65 \%$ of patients. 29 patients are detected to have microcytic anemia and 15 patients have dimorphic anemia.

Figure 2: Cardiac lesions among Congenital heart disease

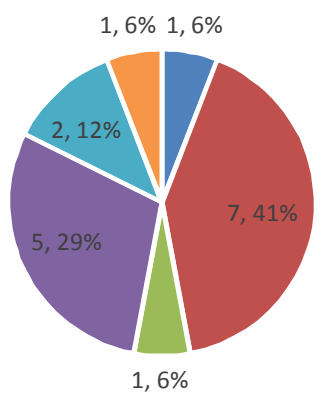

$$
\begin{array}{ll}
\text { - Eisenmenger syndrome } & \text { a VSD } \\
\text { — VSD with severe PAH } & \text { a ASD } \\
\text { - PDA } & \text { a Pulmonary stenosis }
\end{array}
$$

Maximum number of the patients delivered through vaginal (61\%) route. Among 40 patients delivered vaginally, 19 patients undergone instrumental delivery. $37 \%$ of the patients underwent LSCS for various obstetric reasons.

Table 3: History of repair at the time of admission

\begin{tabular}{lll}
\hline History of repair & $\mathbf{N}$ & $\mathbf{\%}$ \\
\hline No & 46 & 69.7 \\
PTMC & 6 & 9.0 \\
PDA repair & 3 & 3.9 \\
ASD closure & 5 & 4.5 \\
Ballonvalvuloplasty & 2 & 3.0 \\
VSD corrected & 2 & 3.0 \\
History of cardiac surgery & 1 & 1.5 \\
Corrected TAPVC & 1 & 1.5 \\
Total & 66 & 100 \\
\hline
\end{tabular}

PTMC - Percutaneous transvenous mitral commissurotomy, PDA -

Patent ductus arteriosus, ASD - Atrial septal defect, VSD - Ventricular septal defect, TAPVC - Total anomalous pulmonary venous connection

4 number of patient delivered IUD (Intrauterine death) baby. About $14.7 \%$ of new born babies had CHD (table 5). 6 newborns had VSD as defect and 3 babies had ASD. All their mothers are in second dominant category that is they have CHD. Since many of the CHDs will close spontaneously after week, we didn't follow the babies after discharge, being the weakness of the study. More than $80 \%$ of the patients were stable following delivery. 3 patients developed atonic postpartum haemorrhage (PPH) among them one patient went in to disseminated intravascular coagulation (DIC). Out of 66 patients 5 patients died, accounting $7.5 \%$ of maternal mortality among cardiac patients.

\begin{tabular}{clll} 
Table 4: Mode of delivery & & \\
\hline Mode of delivery & $\mathbf{N}$ & $\mathbf{\%}$ \\
\hline Undelivered & 1 & 1.5 \\
Vaginal & & 40 & 60.6 \\
1. & Full term vaginal delivery & 20 & 30.30 \\
2. & Ventouse assisted delivery & 15 & 22.72 \\
3. & Forceps delivery & 4 & 6.06 \\
4. & Assisted breech delivery & 1 & 1.5 \\
LSCS & & 25 & 37.8 \\
1. & Emergency LSCS & 19 & 28.78 \\
2. & Elective LSCS & 6 & 9.09 \\
Total & & 66 & 100 \\
\hline LSCS - Lower segment caesarean section & \\
\hline
\end{tabular}

\begin{tabular}{lll}
\multicolumn{2}{l}{ Table 5: Congenital heart disease in new born } & \\
\hline Congenital heart disease in new born & $\mathbf{N}$ & $\mathbf{\%}$ \\
\hline No congenital heart disease & 52 & 85.2 \\
Presence of congenital heart disease & 9 & 14.7 \\
Total & $61^{*}$ & 100.0 \\
\hline
\end{tabular}

\section{Discussion}

Cardiac disease in the pregnancy is a major risk factor for maternal as well as neonatal morbidity and mortality. Women with cardiac disease require special evaluation before and throughout the pregnancy. Our study shows the maternal and fetal outcome of cardiac disease during pregnancy in our hospital which is a tertiary referral centre in Karnataka.

Prevalence of cardiac disease in our study is $0.4 \%$ which was similar to the study done by Indira et al ${ }^{6}(2006)$, Devabhaktuni $\mathrm{P}$ et $\mathrm{al}^{5}$ (2009). But the prevalence is more in the study conducted by Asghar et $\mathrm{al}^{4}(2005)$ and P Sneha et $\mathrm{al}^{7}$ (2014) $0.98 \%$ and $0.87 \%$ respectively. Teaching institute in our country, being the referral centers, may not truly reflect the actual prevalence. It is an important cause of maternal mortality in india ${ }^{3}$.

About $20 \%$ of the patients fall in the category of age between 25-29 years and $8 \%$ above 30 years of age in our study similar to the study by $\mathrm{P}$ Sneha et $\mathrm{al}^{7}$. In our study primigravidas are slightly lower in number than multigravidas which was similar to the study conducted by Mangala et al $^{8}$ and Bagde et al ${ }^{9}$ and T Nqayana et al ${ }^{10}$. Whereas in the study of Indira et al ${ }^{6}$ primigravidas are more than multigravidas. More than $75 \%$ of the patients delivered after completing 37 weeks of gestation which was almost similar to the study conducted by Arnaldo Rodriguez et al ${ }^{11}$.

In almost all of the studies RHD are being the dominant lesion. In our study it contributes to around 54\% which was almost similar to the study conducted by Salam $\mathrm{S}$ et $\mathrm{al}^{12}$ .Whereas some studies shows quite larger number of RHD 
being $66 \%, 69 \%, 80 \%, 88 \%$ respectively ${ }^{3,6,14,15}$. Study conducted by Vidyadhar B Bangal et al $(2012)^{13}$ has low prevalence of RHD as compared to other study. Not only the Indian studies showing RHD as the predominant lesion, a study conducted in South Africa also showed the same percentage ranging from $71-84^{16}$. In a study conducted in Pakistan the ratio of RHD to CHD is $3: 1^{4}$, in contrast to studies of affluent societies where CHD is the dominant lesion $^{17,18}$. Mitral stenosis was the predominant lesion in many studies accounting $69.6 \%, 89.2 \%$ respectively ${ }^{19,20}$. In our study also MS was predominant lesion accounting for $60.3 \%$. In our study Anti streptolysin-O (ASO) test done for RHD cases and found positive in $51.2 \%$ of cases and all RHD cases received penicillin prophylaxsis at our hospital who were not previously received penicillin.

Most of the patients in postpartum period were stable, only a few patients developed complications like breathlessness, hypotension, PPH. Anemia the most important factor especially in this part of Karnataka which may be the significant precipitating factor for the above complications. Even severe anemia was found in 2 cases and associated with one maternal death. Maternal death in our study is quite high compared to other studies contributing to around $7.5 \%$, probably due to associated morbid conditions and late referrals. Studies by T Nqayana et al ${ }^{10}(2008)$ and Vidyadhar B Bangal et al ${ }^{13}(2012)$ shows 0 mortality rate .

\section{Conclusion}

In our study, the incidence of cardiac disease in pregnancy is $0.39 \%$. RHD is the commonest etiology followed by CHD. Mitral stenosis is the commonest lesion in RHD, while VSD is the commonest in CHD. Cardiac disease in pregnancy constitutes high risk, and poses a major impact on mother as well as fetus. This study shows that proper maternal evaluation antenatally, institutional delivery can significantly improve the prognosis of both mother and fetus. In treating such cases a multidisciplinary approach is ideal and team should involve obstetrician, cardiologist, anaesthetist, if necessary cardiac surgeons should be involved.

\section{Conflict of interest: None. Disclaimer: Nil.}

\section{References}

1. Thompson JL, Kuklina EV, Bateman BT, Callaghan WM, James AH, Grotegut CA. Medical and obstetric outcomes among pregnant women with congenital heart disease. Obstet Gynecol. 2015;126: 346-54.
2. Elliott C, Sliwa K, Anthony J. Perinatal Outcome in Pregnant Women with Heart Disease Attending a Combined Obstetric and Cardiology Clinic in a Resource Limited Country. International Journal of Gynecology, Obstetrics and Neonatal Care. 2015; 2: 8-15.

3. Konar H, Chaudhuri S. Pregnancy complicated by maternal heart disease: a review of 281 women. The Journal of Obstetrics and Gynecology of India. 2012 Jun 1; 62(3): 301-6.

4. Asghar F, Kokab H. Evaluation and outcome of pregnancy complicated by heart disease. J Pak Med Assoc. 2005; 55: 416-9.

5. Devabhaktuni P, Devinenik K, Vemuri U. Pregnancy outcome in chronic rheumatic heart disease. J Obstet Gynaecol India. 2009; 59: 41-6.

6. Indira I, Sunitha K. Study of Pregnancy Outcome in Maternal Heart Disease. IOSR Journal of Dental and Medical Sciences (IOSR-JDMS). 2015;1(14):6-10.

7. Sneha P, Sarojamma c, Nagrathnamma R. Cardiac Disease complicating pregnancy: A Tertiary Care Centre Experience. J Med Sci. 2017; 3(2): 41-4

8. Rajput MC, Rajput U, Gandhare S, Jain A. Impact of maternal cardiac disease on pregnancy outcome and to study predictors of cardiac events. 2015; 2(6):1038-45

9. Bagde ND, Bagde MN, Shivkumar PV, Tayade S. Clinical profile and obstetric outcome in pregnancies complicated by heart disease: a five year Indian rural experience. Int $\mathrm{J}$ Reprod Contracept Obstet Gynecol. 2013; 2: 52-7

10. Nqayana T, Moodley J, Naidoo DP. Cardiac disease in pregnancy. Cardiovasc J Afr. 2008; 19(3):145-51.

11. Rodriguez A. No buscado de rebatir el aforismo Hipocrático cor aegrotari non potest. Cor Salud. 2012 Oct-Dec; 4(4): 311-3

12. Salam S, Mushtaq S, Mohi-ud-Din, Gul I, Ali A. Maternal and fetal outcome in pregnancy with heart disease in tertiary care hospital in India. Int $\mathbf{J}$ Reprod Contracept Obste Gynecol. 2017; 6: 3947-51

13. Watkins DA, Sebitloane M, Engel ME, Mayosi BM, Bangal VB, Singh RK, et al. Clinical Study of Heart Disease Complicating Pregnancy. Clinical Study. 2012 Jul; 2(4): 25-8.

14. Mazhar SB. Fetomaternal outcome in pregnancy with cardiac disease. JCPSP. 2005;15(8):476-80 
The New Indian Journal of OBGYN. 2021 (January-June);7(2)

15. Bhatla N, Lal S, Behera G, Kriplani A, Mittal S, Agarwal $\mathrm{N}$, et al. Cardiac disease in pregnancy. Int $\mathrm{J}$ Gynecol Obstet. 2003; 82(2):153-9.

16. Watkins DA, Sebitloane M, Engel ME, Mayosi BM. The burden of antenatal heart disease in South Africa: a systematic review. BMC cardiovascular disorders. 2012 Mar 30;12: 23.

17. Van Mook WNKA, Peeters L. Severe cardiac disease in pregnancy, part II: impact of congenital and acquired cardiac disease during pregnancy. Curr Opin Crit Care. 2005; 11(5): 435-48

18. Thorne SA. Pregnancy in heart disease. Heart 2004; 90: 450-6.

19. Hameed A, Karaalp IS, Tummala PP, Wani OR, Canetti $\mathrm{M}$, Akhter MW, et al. The effect of valvular heart disease on maternal and fetal outcome of pregnancy. J Am Coll Cardiol. 2001;37:893-9.

20. Sawhney H, Aggarwal N, Suri V, Vasishta K, Sharma $\mathrm{Y}$, Grover A. Maternal and perinatal outcome in rheumatic heart disease. Int J Gynaecol Obstet. 2003; 80: 9-14.

Shyamsundar B ${ }^{1}$, Vinayraju $D^{2}$, Seeta Garag ${ }^{3}$ ${ }^{1}$ Department of Obstetrics and Gynecology, KIMS, Hubli, Karanataka, India; ${ }^{2}$ Department of Obstetrics and Gynecology, KIMS, Hubli, Karanataka, India; ${ }^{3}$ Department of Obstetrics and Gynecology, KIMS, Hubli, Karanataka, India. 